\title{
‘Goose bumps'-associated anaemia
}

\author{
Chisho Hoshino, Akane Yamabe, Yoshiyuki Sekikawa, Kana Ishihara, Hiroshi lkeda, Noriyuki Satoh, \\ Masashi Narita, Minoru Inoue
}

Department of General Internal Medicine, Ohta-Nishinouchi Hospital, Koriyama City, Fukushima, Japan

Correspondence to Dr Chisho Hoshino,gim-hoshino@ohta-hp.or.jp

\begin{abstract}
Summary
A 36-year-old woman presented to our hospital for further evaluation of anaemia screened by regular check-up. She was diagnosed with iron-deficiency anaemia (IDA) but refractory to iron supplementation. She had negative results of occult blood in the stool and no gynaecologic disease potentially causing hyper menorrhea. Upper endoscopy revealed a nodular gastritis, which has been called 'Torihada-ien', a Japanese word meaning 'gastritis with goose bumps-like appearance', associated with Helicobacter pylori (Hp) infection. After Hp eradication therapy, her anaemia resolved with an improved response to iron supplementation. In an unexplained IDA patient, Hp-associated gastritis should be considered in the possible background.
\end{abstract}

\section{BACKGROUND}

Iron-deficiency is the most common cause of anaemia in the world, affecting an estimated 2 billion people. ${ }^{1}$ In the UK, approximately $8 \%$ of adult women have iron-deficiency anaemia (IDA) and $11 \%$ have low iron stores without anaemia, according to data from the 2000-01 National Diet And Nutrition Surveys. ${ }^{2}$ In an analysis of consecutive cross-sectional nationwide surveys of anaemia in adult Japanese women during the period $1989-2003,{ }^{3}$ anaemia (haemoglobin $(\mathrm{Hb})<12.0 \mathrm{~g} / \mathrm{dl}$ ) was especially significant in middle aged women, showing its prevalence increased from $16.8 \%$ to $20.6 \%$ in aged $30-39$, and from $20.2 \%$ to $26.9 \%$ in aged $40-49$, respectively. In young women, IDA due to low dietary iron intake or increased iron loss due to heavy menstrual blood loss or chronic disease may be a significant cause. ${ }^{3}$ Here, we present an adult woman case of IDA without evidence of increased iron loss but refractory to iron supplementation. We hope this case report will guide management for such an unexplained IDA.

\section{CASE PRESENTATION}

A 36-year non-pregnant woman visited our hospital for further evaluation of anaemia screened by regular checkup. The anaemia had been evident for several years but had never been taking further investigation or treatment. She had easy fatigability without gastrointestinal (GI) symptom. She was not taking any medication and had no history of pregnancy, GI disease or eating disorder. She maintained a normal diet and reported no weight loss. Her menstrual cycle was regular. On physical examination, the height was $160 \mathrm{~cm}$ and body weight was $54 \mathrm{~kg}$. The blood pressure was $116 / 60 \mathrm{~mm} \mathrm{Hg}$, the pulse rate was 60 beats/min. She appeared slightly pale but no any other abnormality was noted. Results of haematologic profile showed hypochromic microcytic anaemia $(\mathrm{Hb} 8.8 \mathrm{~g} / \mathrm{dl}$, haematocrit $31.6 \%$, mean corpuscular volume 70.1fl, mean corpuscular $\mathrm{Hb} 19.5 \mathrm{pg}$, serum iron 20 $\mu \mathrm{g} / \mathrm{dl}$, total iron binding capacity $429 \mu \mathrm{g} / \mathrm{dl}$, serum ferritin (SF) $3.7 \mu / \mathrm{l})$. The laboratory examination ruled out haemolysis, malnutrition, chronic inflammatory disease and renal failure. The occult blood tests in the stool were negative results. The gynaecologic examination revealed no abnormality potentially causing hyper menorrhea. Based on these investigations, she was diagnosed with IDA and iron supplementation of $60 \mathrm{mg} /$ day was initiated. However, her $\mathrm{Hb}$ and SF levels remained low of 10.2 $\mathrm{g} / \mathrm{dl}$ and $6.8 \mu / 1$, respectively, even after 3 -month appropriate iron supplementation.

\section{INVESTIGATIONS}

${ }^{13} \mathrm{C}$-urea breath test for Helicobacter pylori $(\mathrm{Hp})$ infection showed a positive result for urease activity. Thus, despite negative results of occult GI bleeding, upper endoscopy was performed for assessment of a GI cause for the anaemia, revealing diffuse gastric nodularity 2 to $3 \mathrm{~mm}$ in diameter from the antrum to angulus without any mucosal erosion, ulcer or atrophy (figure 1). No endoscopic abnormalities, including typical markers of celiac disease, were present in the oesophagus and duodenum. On histological examination, biopsy specimens from the antrum and angulus showed marked inflammatory cell infiltration with lymphoid follicles (figure 2). Immunophenotyping study staining with the monoclonal B cell antibody CD-20 to rule out mucosa-associated lymphoid tissue (MALT) lymphoma showed a negative result. Based on these investigations, she was diagnosed having nodular gastritis (NG) associated with Hp infection.

\section{TREATMENT}

$\mathrm{Hp}$ eradication regimen including amoxicillin $1500 \mathrm{mg} /$ day, metronidazole $500 \mathrm{mg} /$ day and rabeprazole $20 \mathrm{mg} /$ day for 7 days was begun with successful eradication (negative result of follow-up with ${ }^{13} \mathrm{C}$-urea breath test).

\section{OUTCOME AND FOLLOW-UP}

Two months after Hp eradication, her haematologic profile returned to normal of $\mathrm{Hb} 14.1 \mathrm{~g} / \mathrm{dl}$ and SF $34.1 \mu / 1$ with an improved response to iron supplementation. One year 


\section{BMJ Case Reports}

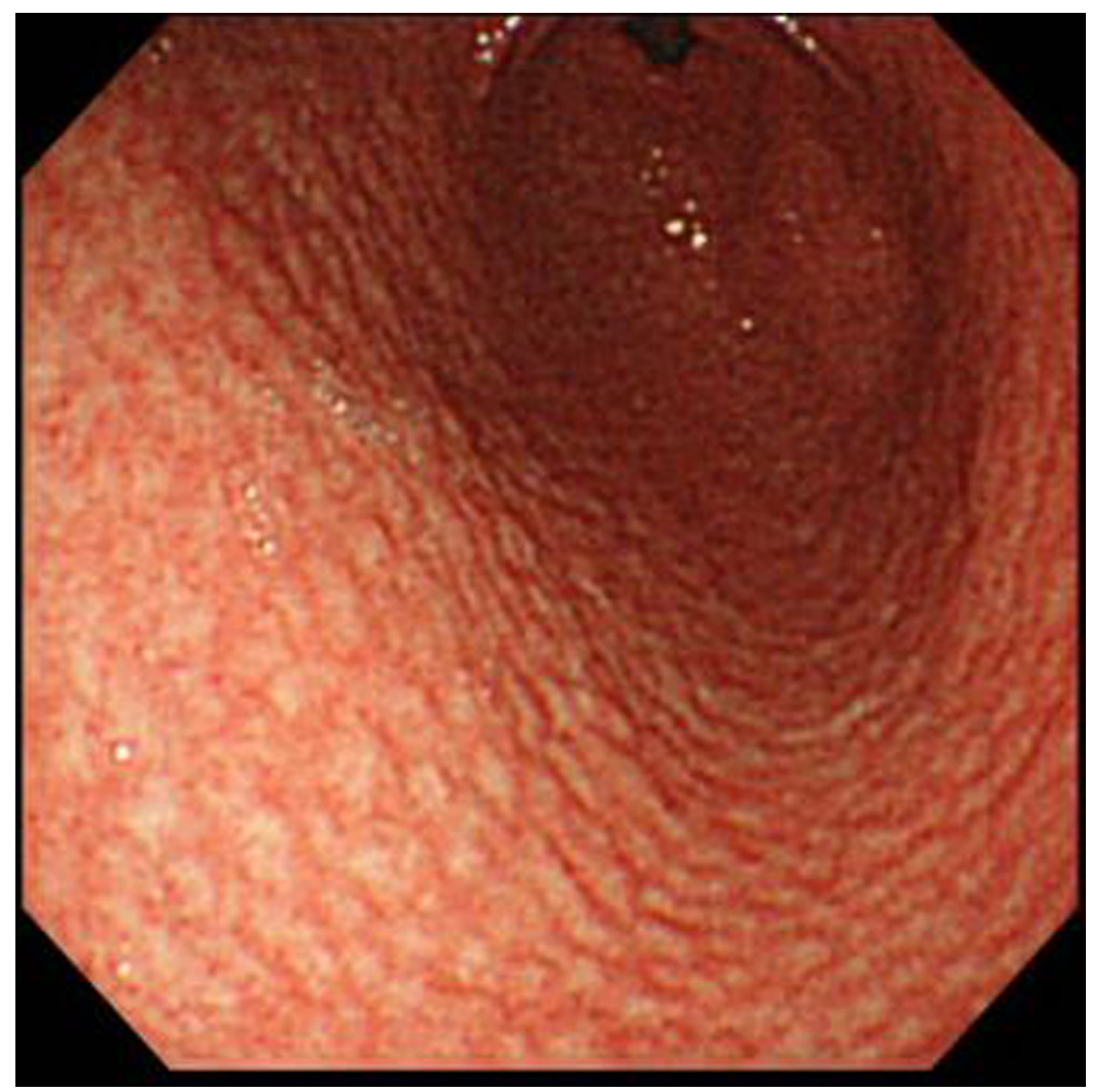

Figure 1 Upper endoscopy revealed diffuse gastric nodularity 2 to $3 \mathrm{~mm}$ in diameter from the antrum to angulus without any mucosal erosion, ulcer or atrophy.

later, her $\mathrm{Hb}$ was maintained almost normal with intermittent iron supplementation.

\section{DISCUSSION}

\section{Clinical significance of NG}

NG is a form of chronic gastritis that endoscopically has a miliary pattern with cobblestone appearance. ${ }^{4}$ In Japan, it has been called 'Torihada-ien', a Japanese word meaning 'gastritis with goose bumps-like appearance'. It is pathologically characterised by prominent lymphoid follicles and infiltration of mononuclear cells in the gastric mucosa. ${ }^{5}$ This phenomenon was once considered physiologically particular to young women. However, recent studies have shown that NG was highly associated with Hp infection with a high specificity $(96.8 \%)$ and positive predictive value $(93.3 \%)^{4}$ and after successful Hp eradication, endoscopic NG pattern disappeared or improved. ${ }^{6}$ In addition, it might be a risk factor for gastric cancer with some specific features. ${ }^{5}$ However, absence of NG cannot rule out $\mathrm{Hp}$ infection due to low sensitivity. ${ }^{4}$ This particular gastritis in patients with $\mathrm{Hp}$ infection may occur resulting from some factors such as variations in Hp strains, individual disease susceptibility, or a complex bacteriahost interaction. ${ }^{6}$

\section{The association between IDA and Hp infection}

In prospective studies of patients with IDA, conventional endoscopic investigation failed to identify a culprit lesion potentially responsible for blood loss in a large proportion of patients. ${ }^{7}{ }^{8}$. Recent epidemiologic studies have suggested a highly association between Hp infection and IDA. In a systematic review, $\mathrm{Hp}$ infection was a risk factor for IDA; pooled odds ratio (OR) $2.8(95 \%$ CI 1.9, 4.2) and also for iron-deficiency; pooled OR 1.38 (95\% CI 1.16-1.65). ${ }^{9}$ In a case series, $91.7 \%$ of IDA patients with Hp-associated gastritis recovered from anaemia even with discontinuation of iron supplementation 12-month after Hp eradication therapy. ${ }^{10}$ In a meta-analysis of IDA patients with $\mathrm{Hp}$ infection, Hp eradication therapy combined with iron supplementation was associated with a more significant increase in haematologic parameters than iron supplementation alone. ${ }^{11}$

\section{The possible pathologic mechanism of IDA associated with Hp infection}

Several mechanisms have been proposed to explain the possible relationship between IDA and Hp infection. Iron in food is available in two forms-hem iron (in muscle as myoglobin and $\mathrm{Hb}$ ), which is readily absorbed, and non- 


\section{BMJ Case Reports}

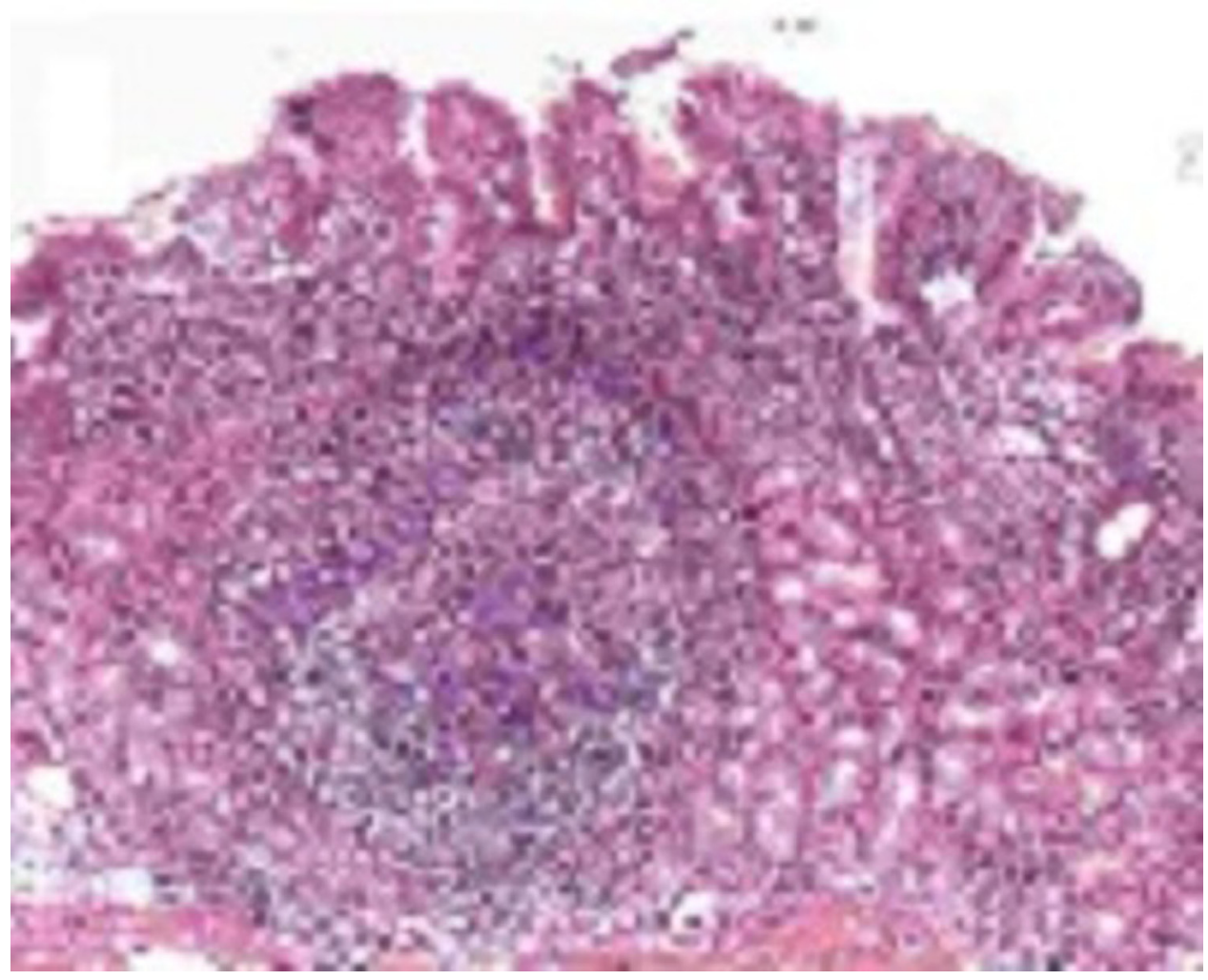

Figure 2 On histological examination, a biopsy specimen from the antrum showed marked inflammatory cell infiltration with lymphoid follicles (Haematoxylin-Eosin stain, $\times 10$ ).

hem iron (in vegetables, cereals and meat), which accounts for $80 \%$ of dietary iron in industrialised countries. ${ }^{12}$ Both hydrochloric acid and ascorbic acid in gastric secretion are essential for the effective solubility and absorption of nonhem iron. ${ }^{12} \mathrm{Hp}$ infection might inhibit the non-hem iron absorption by lowering hydrochloric acid and ascorbic acid concentration in the gastric secretion. ${ }^{13}$

Hp infection might cause IDA by utilising iron for growth, competing with the human host. It has been shown that human lactoferrin (HLf) serves as a source of iron for $\mathrm{Hp}$ in gastric mucosa and Hp produces a HLf-binding protein that is highly specific for HLf. ${ }^{14}$ The level of HLf in gastric mucosa increased in $\mathrm{Hp}$ infection and decreased significantly after $\mathrm{Hp}$ eradication therapy, while the blood $\mathrm{Hb}$ level correspondingly increased. ${ }^{15}$

In a current study, strains of $\mathrm{Hp}$ isolated from IDA patients showed enhanced iron uptake and iron dependent rapid growth compared with those from non-IDA patients. ${ }^{16}$ It has been shown that $\mathrm{Hp}$ binds iron to a specific receptor by iron-repressible outer membrane proteins (IROMPs). ${ }^{17}$ In the iron-depleted state, strains of $\mathrm{Hp}$-associated with IDA demonstrated an advantage in iron acquisition due to a higher expression of IROMPs. ${ }^{17}$ Based on the experimental evidence, colonisation of specific Hp strains with enhanced iron uptake or binding ability might predispose to IDA.

\section{Our comments of the present case}

In case of a refractory IDA, the potential causes should be ruled out. In the present case, careful history taking and laboratory investigations excluded incorrect diagnosis (thalassemia, etc.), presence of coexisting non-GI disease impairing response (haemolysis, chronic inflammation, renal failure, etc.), lack of adherence to medication, concomitant use of drugs impairing response (antacids, etc.). But, given that she needed to take intermittent iron supplementation even after $\mathrm{Hp}$ eradication, we may fail to identify comorbid GI source, in addition to the possibility of relatively low dietary iron intake compared with regular menstrual iron loss as with typical Japanese IDA women.

Based on current literature, autoimmune atrophic gastritis and celiac disease as well as Hp infection have been proposed as significant factors in refractory or unexplained IDA. ${ }^{18}$

Autoimmune atrophic gastritis is manifested by hypergastrinaemia in combination with antiparietal antibodies. ${ }^{18}$ Despite no data of serum gastrin concentration or antiparietal antibody titers in this case, both endoscopic findings and histopathology excluded the condition.

In western countries, celiac disease should be considered in the differential diagnosis of IDA and needs histopathology to confirm a definite diagnosis. However, she had neither characteristic GI or extra-GI manifestations nor typical endoscopic markers associated with celiac disease. ${ }^{19}$ The possibility of coexisting subclinical condition may be considered but less likely due to the extremely low prevalence in Japan. ${ }^{20}$

Occasionally, gastric MALT lymphoma can occur endoscopically in cobblestone appearance, which is hard to differentiate from NG. However, she had a negative immunophenotyping study.

In the present case, Hp infection was likely to be one of significant factors predisposing to refractory IDA because successful $\mathrm{Hp}$ eradication readily improved response to iron supplementation. However, careful follow-up, 


\section{BMJ Case Reports}

regardless of repeatedly negative results of occult blood in the stool, is required and further GI investigations including work-up for colonic or small bowel lesions should be taken into consideration if refractory IDA progresses during the course.

\section{CONCLUSION}

In a refractory IDA patient, Hp infection should be considered in the possible background. In such an unexplained IDA patient, a search for Hp-associated gastritis should be undertaken even when GI manifestation is absent. NG is highly associated with $\mathrm{Hp}$ infection with a high specificity and positive predictive value. Hp eradication could improve haematologic parameters along with an improved response to iron supplementation.

\section{Learning points}

- In a refractory IDA patient, Hp infection should be considered in the possible background.

- In such an unexplained IDA patient, a search for $\mathrm{Hp}$-associated gastritis should be undertaken even when $\mathrm{Gl}$ manifestation is absent.

- NG is highly associated with Hp infection with a high specificity and positive predictive value.

- Hp eradication could improve haematologic parameters along with an improved response to iron supplementation.

\section{Competing interests None.}

Patient consent Obtained.

\section{REFERENCES}

1. Zimmermann MB, Hurrell RF. Nutritional iron deficiency. Lancet 2007;370:511-20.

2. Fairweather-Tait SJ. Iron nutrition in the UK: getting the balance right. Proc Nutr Soc 2004;63:519-28.
3. Hayashi F, Yoshiike N, Yoshita K, et al. Trends in the prevalence of anaemia in Japanese adult women, 1989-2003. Public Health Nutr 2008:11:252-7.

4. Al-Enezi SA, Alsurayei SA, Aly NY, et al. Endoscopic nodular gastritis in dyspeptic adults: prevalence and association with Helicobacter pylori infection. Med Princ Pract 2010:19:40-5

5. Kamada T, Hata J, Tanaka A, et al. Nodular gastritis and gastric cancer. Dig Endosc 2006;18:79-83.

6. Chen MJ, Shih SC, Wang TE, et al. Endoscopic patterns and histopathological features after eradication therapy in Helicobacter pylori-associated nodular gastritis. Dig Dis Sci 2008;53:1893-7.

7. Rockey DC, Cello JP. Evaluation of the gastrointestinal tract in patients with iron-deficiency anemia. N Eng/ J Med 1993;329:1691-5.

8. McIntyre AS, Long RG. Prospective survey of investigations in outpatients referred with iron deficiency anaemia. Gut 1993;34:1102-7.

9. Muhsen K, Cohen D. Helicobacter pylori infection and iron stores: a systematic review and meta-analysis. Helicobacter 2008;13:323-40.

10. Annibale B, Marignani M, Monarca B, et al. Reversal of iron deficiency anemia after Helicobacter pylori eradication in patients with asymptomatic gastritis. Ann Intern Med 1999;131:668-72.

11. Huang $\mathbf{X}, \mathrm{Ou} X, \mathrm{Yan} W$, et al. Iron deficiency anaemia can be improved after eradication of Helicobacter pylori. Postgrad Med J 2010;86:272-8.

12. Lombard M, Chua E, O'Toole P. Regulation of intestinal non-haem iron absorption. Gut 1997; 40:435-9.

13. Annibale B, Capurso G, Lahner E, et al. Concomitant alterations in intragastric $\mathrm{pH}$ and ascorbic acid concentration in patients with Helicobacter pylori gastritis and associated iron deficiency anaemia. Gut 2003;52:496-501.

14. Dhaenens L, Szczebara F, Husson MO. Identification, characterization, an immunogenicity of the lactoferrin-binding protein from Helicobacter pylori. Infect Immun 1997;65:514-8.

15. Choe YH, Oh YJ, Lee NG, et al. Lactoferrin sequestration and its contribution to iron-deficiency anemia in Helicobacter pylori-infected gastric mucosa. $J$ Gastroenterol Hepatol 2003;18:980-5.

16. Yokota S, Konno M, Mino E, et al. Enhanced Fe ion-uptake activity in Helicobacter pylori strains isolated from patients with iron-deficiency anemia. Clin Infect Dis 2008;46:e31-3.

17. Lee JH, Choe YH, Choi YO. The expression of iron-repressible outer membrane proteins in Helicobacter pylori and its association with iron deficiency anemia. Helicobacter 2009;14:36-9.

18. Hershko C, Hoffbrand AV, Keret D, et al. Role of autoimmune gastritis, Helicobacter pylori and celiac disease in refractory or unexplained iron deficiency anemia. Haematologica 2005;90:585-95.

19. Dickey W. Endoscopic markers for celiac disease. Nat Clin Pract Gastroenterol Hepatol 2006;3:546-51.

20. Cummins AG, Roberts-Thomson IC. Prevalence of celiac disease in the AsiaPacific region. J Gastroenterol Hepatol 2009;24:1347-51.

This pdf has been created automatically from the final edited text and images.

Copyright 2011 BMJ Publishing Group. All rights reserved. For permission to reuse any of this content visit http://group.bmj.com/group/rights-licensing/permissions.

BMJ Case Report Fellows may re-use this article for personal use and teaching without any further permission.

Please cite this article as follows (you will need to access the article online to obtain the date of publication).

Hoshino C, Yamabe A, Sekikawa Y, Ishihara K, Ikeda H, Satoh N, Narita M, Inoue M. 'Goose bumps'-associated anaemia. BMJ Case Reports 2011; 10.1136/bcr.06.2011.4419, date of publication

Become a Fellow of BMJ Case Reports today and you can:

- Submit as many cases as you like

- Enjoy fast sympathetic peer review and rapid publication of accepted articles

- Access all the published articles

- Re-use any of the published material for personal use and teaching without further permission

For information on Institutional Fellowships contact consortiasales@bmjgroup.com

Visit casereports.bmj.com for more articles like this and to become a Fellow 